4. The following ions are reduced only very slowly or not at all: $\mathrm{TeO}_{4}^{--}$, $\mathrm{PtCl}_{6} \cdots$.

San franctsco, Calif.

\title{
CRYSTALLIZATION OF A RADIUM-BARIUM SOLUTION.
}

\section{By Clareince E. Schort.}

Received January 6, 1919.

Radium of any degree of purity may be obtained by fractional crystallization of a radium-barium solution. The crystal fractions are progressively enriched with radium while the mother liquor fractions are progressively impoverished as the number of crystallizations increases. A system containing several fractions can be divided into 2 parts: first the increasing of the radium and the decreasing of the barium content commonly called the positive series (direction) and second the increasing of the baritum and the decreasing of the radium content commonly called the negative series (direction). In such a system the original material enters the system at some point between the ends while high grade radium (low grade bariutm) comes out the positive end and high grade barium (low grade radium) comes out the negative end. The size of the different fractions decreases gradually toward the positive end and increases toward the negative end. Any soluble impurity occurring in the system stays in the mother liquor and finally passes out of the system with the barium without causing any disturbance. Any insoluble impurity present is occluded in the crystals and is carried toward the positive end with the crystals.

The negative ion ustally employed in the system is the chloride or the bromide. The bromides of radium and barium are more soluble than the chlorides. About $50 \%$ of the total chlorides crystallize out upon cooling a neutral solution from 100 to $0^{\circ}$, while only about $33 \%$ of the total bromides crystallize out under like conditions; yet the quantity of crystals obtained from the same volume of either a chloride or a bromide solution is approximately the same which suggests that the bromide system would be more efficient than the chloride system.

\section{Theoretical.}

The concentration of the radium in any dish in the positive direction may be calculated from the equation

$$
C=A K^{n}
$$

where $n$ is the number of crystallizations, $A$ the known concentration of some dish to start with and $K$ the factor of enrichment-the relative concentration of radium in the crystals to radium in the original material.

Thus if the concentration of radium in the original material be taken as I.O and the concentration of radium in the crystals is 1.6 times the 
concentration of radium in the original material; the concentration of radium in the first dish becomes I. 6 ; the second dish, 2.56 ; the third dish, 4.09 , etc.

The concentration of any dish in the negative direction can be calculated from the equation

$$
C^{\prime}=A^{\prime}\left(\frac{X-K}{X-1}\right)^{m}
$$

where $X$ is the inverse fractional proportion of the total weight of material occurring as crystals and $m$ the number of crystallizations in the minus direction.

Thus with the previously mentioned conditions and half the material as crystals the concentration of radium in the first minus dish becomes 0.40 , the second 0.16 , the third 0.064 , etc.

In any complete system of crystallizing, the positive series and the negative series must be a unified whole that is a system in which both series fit together like $\operatorname{cog}$ wheels. Each dish in the positive direction must conform with a dish in the negative direction. However, this does not mean that the crystals of each dish must necessarily go in the next dish positively or that the mother liquor of every dish must go in the next dish negatively. The crystals may go into the second, third, or the fourth dish positively, while the mother liquors may go into the second, third, or fourth dish negatively, depending upon the value of the enrichment factor $K$.

In order to find the value of $K$, conditions must be chosen in which $A_{1}$ $n, m$, are known. These conditions are: (I) the material used or going into the system must be uniform and of known concentration ( $A$ is constant); (2) the temperature and concentration of maximum heating must. be kept uniform; (3) the temperature and concentration of minimum cooling must be kept uniform; (4) the speed of cooling must be uniform; (5) the concentration of acid must be constant; (6) the value of $X$ must be constant; (7) the same negative ion must be used. The value of $X$ depends partially on Conditions 2, 3,4 and 5 .

\section{Experimental. \\ The Chloride System.}

Hydrochloric acid in quantities ranging from 0.25 to $2.0 \mathrm{~N}$ was added to several portions of a radium-barium chloride solution $\left(\mathrm{ro}^{-2} \mathrm{~g}\right.$. of radium per kg. of barium as sulfate). The dishes containing the several portions were heated on a water bath $\left(95^{\circ}\right)$ until a saturated solution was obtainedthe crystals persisting 30 seconds when the solution is blown. The dishes were then removed from the steam bath, covered and allowed to cool 20 hours in a room of constant temperature at $20^{\circ}$. The mass was then run through a small centrifugal, the crystals weighed and the percentage 
of total material calculated. The radium in the crystals and the mother liquor was then determined quantitatively according to the emanation method as developed by Wilson, Scholl, and later Lind, ${ }^{1}$ with the follow. ing results:

\section{TABLE I.}

Radium-Barium Chloride Solutions Crystallized with Various Quantities of Hydrochloric Acid.

$\begin{array}{cccc}\begin{array}{c}\mathrm{ACl} \text { in solution. } \\ N .\end{array} & \begin{array}{c}\mathrm{BaCl}_{2} \text { in form of } \\ \text { crystals. } \% .\end{array} & \begin{array}{c}\text { Ra in form of } \\ \text { crystals. } \% .\end{array} & \begin{array}{c}\text { Factor of enrich- } \\ \text { ment. }\end{array} \\ 0.25 & 44.0 & 72.6 & 1.65 \\ 0.50 & 50.0 & 81.0 & 1.62 \\ 0.75 & 51.4 & 82.7 & 1.61 \\ 1.0 & 54.3 & 85.8 & 1.58 \\ 2.0 & 58.3 & 87.0 & 1.49\end{array}$

When the acidity is $0.5 \mathrm{~N}$ half of the material in solution crystallizes out. This acidity was chosen for further work as it produces a value of $X$ which can be expressed in a small whole integral.

Several solutions of various radium contents were taken and to each of these sufficient hydrochloric acid was added to make the solution $0.5 \mathrm{~N}$ when starting to cool. They were then crystallized as previously with the following results:

TABLE II.

Radium-Barium Chloride Solutions Crystallized with Various Quantities of Radium.

$\begin{array}{cccc}\begin{array}{c}\text { Ra in solution. } \\ \text { G. per g. of BaSO }\end{array} & \begin{array}{c}\text { BaCla in form of } \\ \text { erystals. } \% .\end{array} & \begin{array}{c}\mathrm{Ra} \text { in form of } \\ \text { crystals. } \%\end{array} & \begin{array}{c}\text { Factor of enrich- } \\ \text { ment. }\end{array} \\ 10^{-1} & 50.5 & 83.0 & 1.64 \\ 10^{-2} & 50.2 & 82.0 & 1.63 \\ 10^{-8} & 50.0 & 81.1 & 1.62 \\ 10^{-4} & 50.1 & 80.8 & 1.61 \\ 10^{-8} & 49.8 & 81.0 & 1.63 \\ 10^{-8} & 49.8 & 80.0 & 1.61\end{array}$

Value of $K$ for the chloride system under the conditions given becomes I.62, and

$$
\begin{aligned}
& C=A \text { г } 6^{n} \\
& C^{\prime}=A 0.4^{m} .
\end{aligned}
$$

If $\mathrm{I}$.o be taken for the concentration of the original material then the relative concentration of the different dishes in the system will be as shown in Fig. x. (Crystals right, liquors left.)

In this chloride system, the crystals move one dish forward for each crystallization, while the liquors move to the second dish to the left. The concentration of the later dishes is exactly the concentration of the first dishes. No other system where half the material crystallizes out can be made with any factor as the slightest variation of the factor in either direc-

Bur. Mines, Bull. 104, 87. 


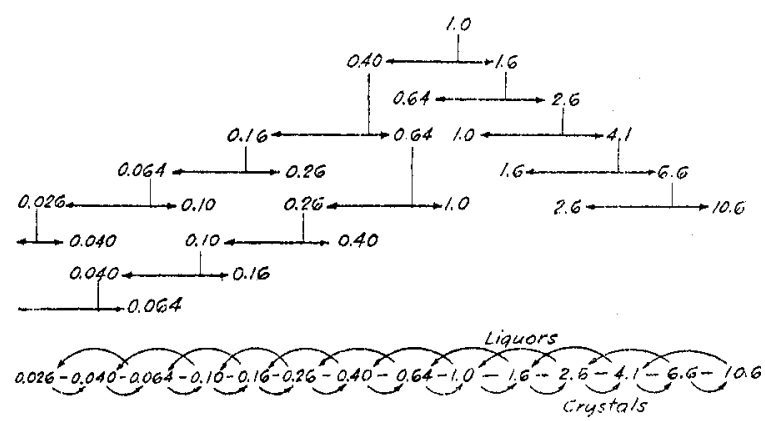

Fig. I.

tion allows no combining of dishes and actually destroys the system. See Fig. 2. Here a system was attempted with a factor of I.8, resulting in no system whatever.

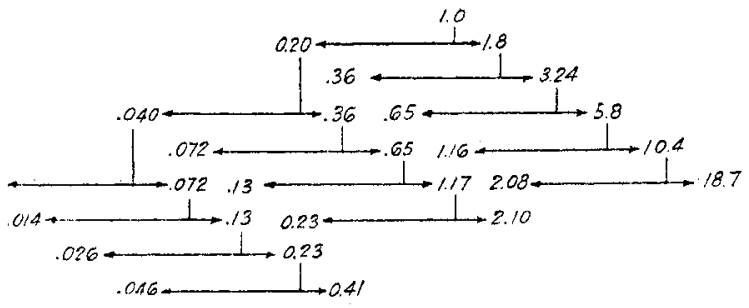

Fig. 2.

\section{The Bromide System.}

Several portions of a radium-barium bromide solution free from im. purities and containing various quantities of hydrobromic acid were treated in a similar manner to the chloride solutions with the following results:

\section{TABLE III.}

Radium-Barium Bromide Solutions Crystallized with Various Quantities of Hydrobromic Acid.

$\begin{array}{cccc}\begin{array}{c}\text { FrB in solution. } \\ N .\end{array} & \begin{array}{c}\text { BaBrin form of } \\ \text { crystals. \% }\end{array} & \begin{array}{c}\text { Ra in form of } \\ \text { erystals. } \% .\end{array} & \begin{array}{c}\text { Factor of enrich- } \\ \text { ment. }\end{array} \\ 0.25 & 30.0 & 78.0 & 2.60 \\ 0.33 & 33.5 & 83.0 & 2.48 \\ 0.50 & 35.0 & 87.0 & 2.49 \\ 0.75 & 36.0 & 89.2 & 2.48 \\ 1.0 & 38.2 & 93.4 & 2.45\end{array}$

When the acidity is $0.33 \mathrm{~N}$ a third of the material in solution crystallizes out. This acidity was chosen for further work as it produces a value of $X$ which can be expressed in a small whole integral.

Several radium-barium bromide solutions of various concentrations of radium and acidified with hydrobromic acid $(0.33 N)$ were crystallized with the following results: 
TABLE IV.

Radium-Barium Bromide Solutions Crystallized with Various Quantities of Radium.

\begin{tabular}{|c|c|}
\hline $\begin{array}{l}\text { Ra in solution. } \\
\mathrm{G} \text { per } \mathrm{g} \text {. of } \mathrm{BaSO}_{4} \text {. }\end{array}$ & $\begin{array}{l}\mathrm{BaBr}_{2} \text { in form of } \\
\text { crystals. } \% \text {. }\end{array}$ \\
\hline $10^{-\frac{1}{1}}$ & 33.6 \\
\hline $10^{-2}$ & $33 \cdot 4$ \\
\hline $10^{-4}$ & $33 \cdot 5$ \\
\hline $10^{-6}$ & $33 \cdot 3$ \\
\hline $10^{-8}$ & $33 \cdot 4$ \\
\hline
\end{tabular}

Ra in form of
crystals. \%.
83.9
82.9
83.0
83.1
83.3

Factor of enricla ment. $K$.

2.50

$2 \cdot 4^{8}$

$2 \cdot 4^{8}$

2.49

2.49

Thus $K$ becomes 2.49 for the bromide system under these conditions and

$$
\begin{aligned}
C & =A 2.49^{n} \\
C^{\prime} & =A 0.25^{m}
\end{aligned}
$$

If $\mathrm{I}$. o be taken for the concentration of the original material then the relative concentration of the different dishes in the system will be shown in Fig. 3. (Crystals right, liquor left.)

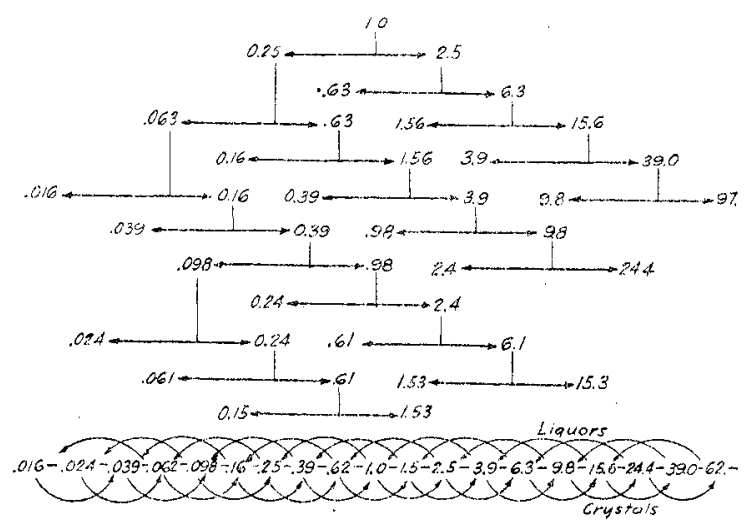

Fig. 3.

In this method the crystals move to the second dish to the right while the liquors move to the third dish to the left. The number of dishes is the same as in the chloride system for the same variation in concentration. The dishes are much smaller in size than those in the chloride system.

A simpler but less efficient method can be calculated with a factor of 2.0 and $1 / 3$ of the barium as crystals. See Fig. 4.

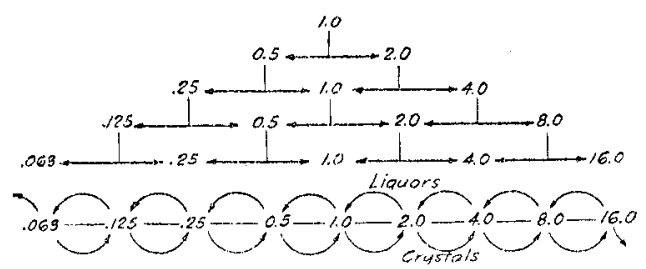

Fig. 4. 
In this method the crystals move one dish to the right while the liquors move one dish to the left. This is the method ${ }^{1}$ commonly used for crystallizing radium-barium solutions. The concentration in the negative direction actually decreases a great deal faster than is represented in the figure. Usually a great deal of unnecessary crystallization is made as the crystals always contain more radium and the liquors less radium than the system shows. The only advantage obtained is a smaller number of dishes in the system. With this exception there is no other system of any factor in which $1 / 3$ of the barium can be crystallized and still have dishes of the same concentration so that they may be combined.

There are, however, 2 variations of the system with 2.5 factor and $1 / 8$ of the material as crystals that should be considered. First, Dishes $+\mathrm{I}$ and $+2,+4$ and $+5,+7$ and +8 , etc., of the positive series, and $-\mathrm{r}$ and $-2,-4$ and $-5,-7$ and -8 , etc., of the negative series can be combined, producing a system having nearly the same concentration in the dishes as the system with a factor of 2.0 , but with these differences. The liquors move 2 dishes to the left instead of one, while the crystals contain a higher concentration of radium than the next dish in the positive direction. Thus a system is obtained with less dishes in which the liquors fall in dishes of like concentration while the crystals do not. See $A$, Fig. 5 .
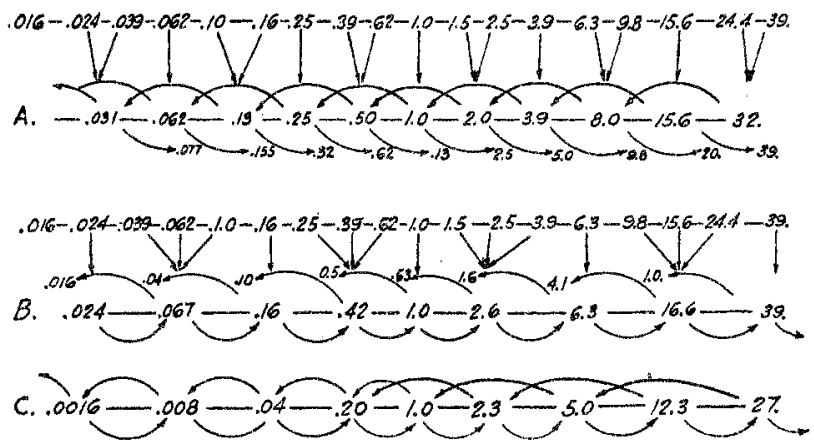

Fig. 5.-Liquors above, crystals below.

Second, Dishes $+\mathrm{I},+2$ and $+3,+5,+6$ and +7 , and +9 , + Io and $+\mathrm{II}$, etc., of the positive series, and $-\mathrm{I},-2$ and $-3,-5,-6$ and -7 , -9, - - ro and - I I, etc., of the negative series, can be combined, producing a system of fewer dishes in which the crystals fall in dishes of like concentration while the liquors do not. Here the crystals move one dish to the right while the concentrations of the liquors are greater than that in the second dish to the left and less than that in the first dish to the left. See $B$, Fig. 5 .

${ }_{1}$ Bur. Mines, Bull. 104, p. 74. 
These 2 variations are most suited for a practical system of crystallization. The concentrations of the dishes of the first variation correspond with the concentration of the dishes in the system of factor 2.0 and $1 / 3$ of the material as crystals, while the concentrations of the second variation are slightly higher. By placing the crystals of the first variation in the first dish to the right as in the second variation, or by placing the liquors of the second variation in the second dish to the left as in the first variation, a system is obtained in which the concentration of the different dishes would be between the concentration of the dishes in the 2 variations, with the crystals and liquors moving as in the chloride system.

Some of the efficiency of the system is lost but the number of dishes is cut in half, eliminating a great deal of labor, which more than balances the loss in efficiency.

The negative dishes can be combined further and run as stated previously, moving the crystals one dish forward and the liquors one dish backwards. See $C$, Fig. 5. This would put the liquor from the first dish in the enrichmient series into the $-\mathrm{r}$ dish. The quantity of crystals can also be increased slightly, producing a greater percentage of the radium (lower concentration) in the crystals and keeping the quantity of radium in the tailings constant and at a minimum.

\section{Facts Noticed during Crystallization.}

Some evidence was obtained that a salt of the composition of $\mathrm{RaBr}_{2}$-$2 \mathrm{BaBr}_{2} .6 \mathrm{H}_{2} \mathrm{O}$ was formed in the crystals from slightly acid solutions, having as a final product of the crystallizing system a salt containing about $39 \%$, dry weight, of radium bromide. Higher concentrations of radium salts have been made using more concentrated acid solutions. Either on account of the small quantity of material worked with, or the effect of high concentration of radium, or the formation of this complex salt, more radium remained in solution than could be accounted for, necessitating a larger number of crystallizations.

For proportional increase in radium concentration it is more difficult to crystallize high concentrations of radium than low concentrations of radium.

The effect of a low concentration (Ioo micrograms of radium element per $\mathrm{kg}$. of barium as sulfate) is very marked if occurring with a high concentration of acid (over $2 \mathrm{~N}$ ). With these conditions the enrichment of radium is reversed, more radium $(55 \%)$ occurring in the liquor than in the crystals $(45 \%)$. This condition can only be remedied by evaporating to dryness and dissolving in water with the right concentration of acid.

The greater the acidity the greater the quantity of crystals and the smaller the factor. The lower the acidity in the solution the smaller the quantity of crystals and the greater the factor. 
The first crystals formed in any solution contain more radium than any of the later crystals.

The concentration of radium in the crystals increases with the time of crystallization for equal quantities of crystals from solutions of the same radium concentration.

In neutral or alkaline solutions radium-barium crystals form extremely slowly upon cooling, supersaturation being noticeable. Acid in the solutions seems to act as a catalyzer in forming crystals, supersaturation being less noticeable.

\section{Summary.}

Several systems of crystallizing a radium-barium solution are given with a modified form that is very efficient in crystallizing high grade radium.

The bromide system is more efficient than the chloride system.

Radium is much easier to separate from barium than formerly supposed.

Several important conditions of crystallization are noted.

DENVRR, COLORADO.

[CONTRibution from the Chemical Laboratory of the University of CaliFORNIA.]

\section{DETERMINATION OF THE EQUILIBRIUM BETWEEN CHLORINE,} WATER, HYDROCHLORIC ACID AND CHLORIC ACID. THE FREE ENERGY OF THE CHLORATE ION.

By AXEL R. OI,SON.

Received January 27, 1920.

The object of this research was to determine the equilibrium constant, for which no direct measurements exist, of the following reaction:

$$
{ }_{3} \mathrm{H}_{2} \mathrm{O}+{ }_{3} \mathrm{Cl}_{2}=\mathrm{HClO}_{3}+{ }_{5} \mathrm{HCl}
$$

The kinetics of this reaction have been studied by variots observers, in particular Sands, ${ }^{1}$ Foerster, ${ }^{2}$ Luther and MacDougall. ${ }^{3}$ Sands attempted to calculate the equilibrium constant from reaction velocities. While this method of obtaining it is correct, it involves certain differential equations which must first be determined. Luther and MacDougall have shown that the differential equation expressing the velocity of the reverse reaction of $(\mathrm{I})$ is not

$$
\mathrm{d} x / \mathrm{d} t=K\left(\mathrm{ClO}_{3}^{-}\right)\left(\mathrm{Cl}^{-}\right)^{2}\left(\mathrm{H}^{+}\right)^{2}
$$

as assumed by Sands, but

$$
\mathrm{d} x / \mathrm{d} t=K\left(\mathrm{ClO}_{3}^{-}\right)^{2}\left(\mathrm{Cl}^{-}\right)^{2}\left(\mathrm{H}^{+}\right)^{4} .
$$

${ }^{1}$ Sands, Z. physik. Chem., 50, 465 (1904).

2 Foerster, J. prakt. Chem., 63, I4I (I9OI).

${ }^{3}$ I.uther and MacDougall, Z. physik. Chem., 62, J99 (1908). 